\title{
Spontaneous Migration of a Ventriculoperitoneal Shunt into the Venous System: A Multidisciplinary Approach
}

\author{
Megan M. Finneran ${ }^{1}$, Emilio Nardone ${ }^{2}$, Dario A. Marotta ${ }^{3,4}$, Glen B. Smith ${ }^{5}$, Ajeet Gordhan ${ }^{6}$ \\ 1. Neurosurgery, Advocate BroMenn Medical Center, Normal, USA 2. Neurosurgery, Central Illinois Neuroscience \\ Foundation, Bloomington, USA 3. Department of Research, Alabama College of Osteopathic Medicine, Dothan, USA 4. \\ Department of Neurology, Division of Neuropsychology, University of Alabama, Birmingham, USA 5. Cardiothoracic \\ Surgery, OSF St. Joseph Medical Center - OSF Healthcare, Bloomington, USA 6. Neurointerventional Radiology and \\ Surgery, OSF St. Joseph Medical Center - OSF Healthcare, Bloomington, USA
}

Corresponding author: Megan M. Finneran, megan.finneran@carle.com

\begin{abstract}
Ventriculoperitoneal shunt catheter migration is a rare but documented complication. The exact mechanism of this occurrence is not well understood. We report the case of an 81-year-old male who initially presented with symptoms consistent with normal pressure hydrocephalus. A ventriculoperitoneal shunt was placed uneventfully. Four months later, the patient presented complaining of a persistent headache despite multiple adjustments in the shunt setting. Shunt series radiographs demonstrated the distal catheter passing through the superior vena cava and looping into the right cardiac atrium and ventricle. Catheter retrieval was attempted from a proximal retroauricular incision but required a combination of snare technique by interventional radiology and, ultimately, surgical venotomy by a cardiothoracic surgeon. The distal catheter was replaced in the abdomen, and the patient had no further complications. This case is the first of its kind reported in the literature that includes a treatment team comprising neurosurgery, interventional radiology, and cardiothoracic surgery. We highlight the importance of a multidisciplinary approach to best address the migrated catheter.
\end{abstract}

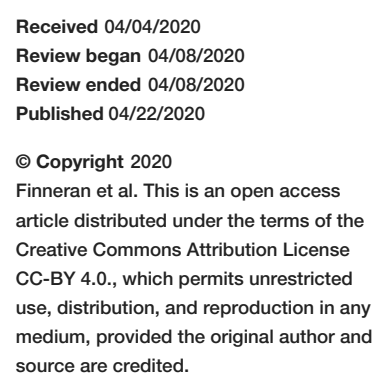
source are credited.
Categories: Cardiac/Thoracic/Vascular Surgery, Radiology, Neurosurgery

Keywords: ventriculoperitoneal shunt, catheter migration, venous system, cardiopulmonary vasculature

\section{Introduction}

Ventriculoperitoneal (VP) shunt placement is a common neurosurgical procedure that occurs around 30,000 times per year in the United States [1]. VP shunting is most frequently used to treat hydrocephalus. Persons treated for normal pressure hydrocephalus have better functional outcomes and lower complication rates than those treated for other indications [2]. Nevertheless, VP shunt complication rates remain relatively high. The incidence of VP shunt malfunctions requiring surgical revision occurs in approximately $15 \%$ of adult patients with VP shunts and is associated with increased age, prolonged hospital stays, and lower Glasgow coma scales [3]. The majority of complications result from overdrainage of cerebrospinal fluid (CSF), which can usually be managed with nonsurgical valve adjustments [4]. Infections, bleeding, CSF leak, and shunt migration are also known VP shunt complications. In this case, we report the intracardiopulmonary migration of a distal VP shunt catheter in an 81-year-old man. We used a multidisciplinary approach involving interventional radiology, cardiothoracic surgery, and neurological surgery to strategically revise the placement of the migrated shunt.

\section{Case Presentation}

\section{History and examination}

An 81-year-old male with an extensive medical history, including lung cancer status post-lobectomy, restless leg syndrome, depression, and peripheral artery disease, presented to the neurosurgical clinic for evaluation of frequent falls. The patient reported backward falls with associated dizziness, confusion, and memory issues. He denied problems with urination. Magnetic resonance imaging (MRI) and computed tomography (CT) of the head showed frontotemporal atrophy and ventriculomegaly that was out of proportion for the atrophy. A neurologist had diagnosed the patient with normal pressure hydrocephalus. Gait was unsteady, but otherwise he had no neurological deficits on examination.

A right-sided VP shunt with a Codman Hakim programmable valve (Integra LifeSciences Corporation, Princeton, NJ, USA) was placed without complication. The shunt pressure was set to $12 \mathrm{~cm} \mathrm{H2O}$. The patient was discharged home on post-operative day 1 with no neurological deficits.

He presented to the office two weeks later with mild-to-moderate positional headache. CT of the head showed the catheter within the ventricular system (Figure 1). 


\section{Cureus}

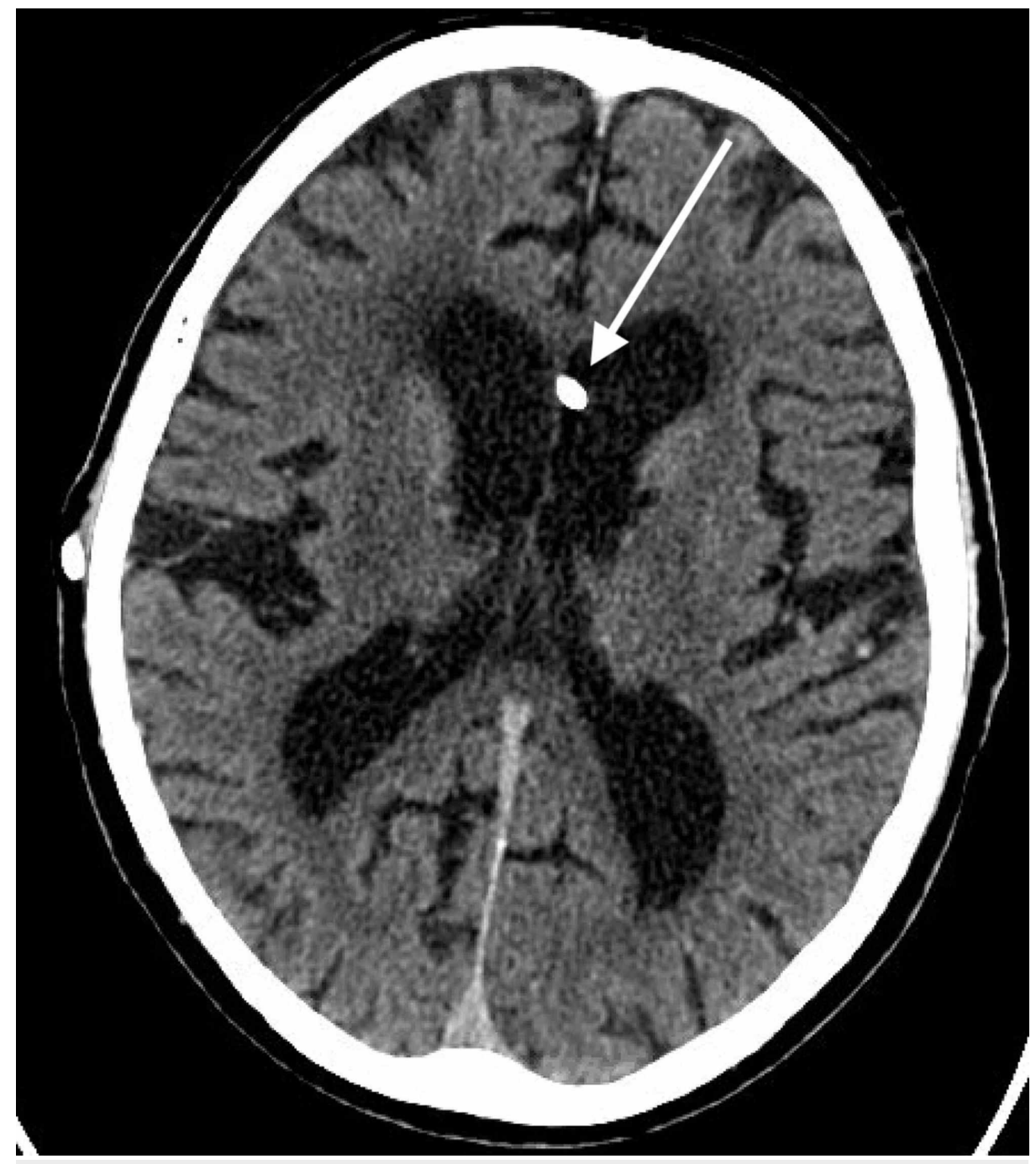

FIGURE 1: Computed tomography (CT) of the head without contrast performed during workup for the patient's headaches shows tip of the proximal catheter within the left lateral ventricle.

The shunt setting was adjusted from $12 \mathrm{~cm} \mathrm{H}_{2} \mathrm{O}$ to $14 \mathrm{~cm} \mathrm{H}_{2} \mathrm{O}$, which was confirmed on skull X-ray. His symptoms initially resolved, but the patient presented to the office one month later with bifrontal headache, nasal drainage, and congestion; he was undergoing a workup for sinusitis by his primary care provider. On physical examination, gait was steady and he had no neurological deficits. Three months post-operatively, the patient reported persistent headache.

At that time, shunt series radiographs were performed and demonstrated migration of the distal aspect of the shunt catheter through the superior vena cava (SVC) into the right side of the heart (Figure 2). 


\section{Cureus}

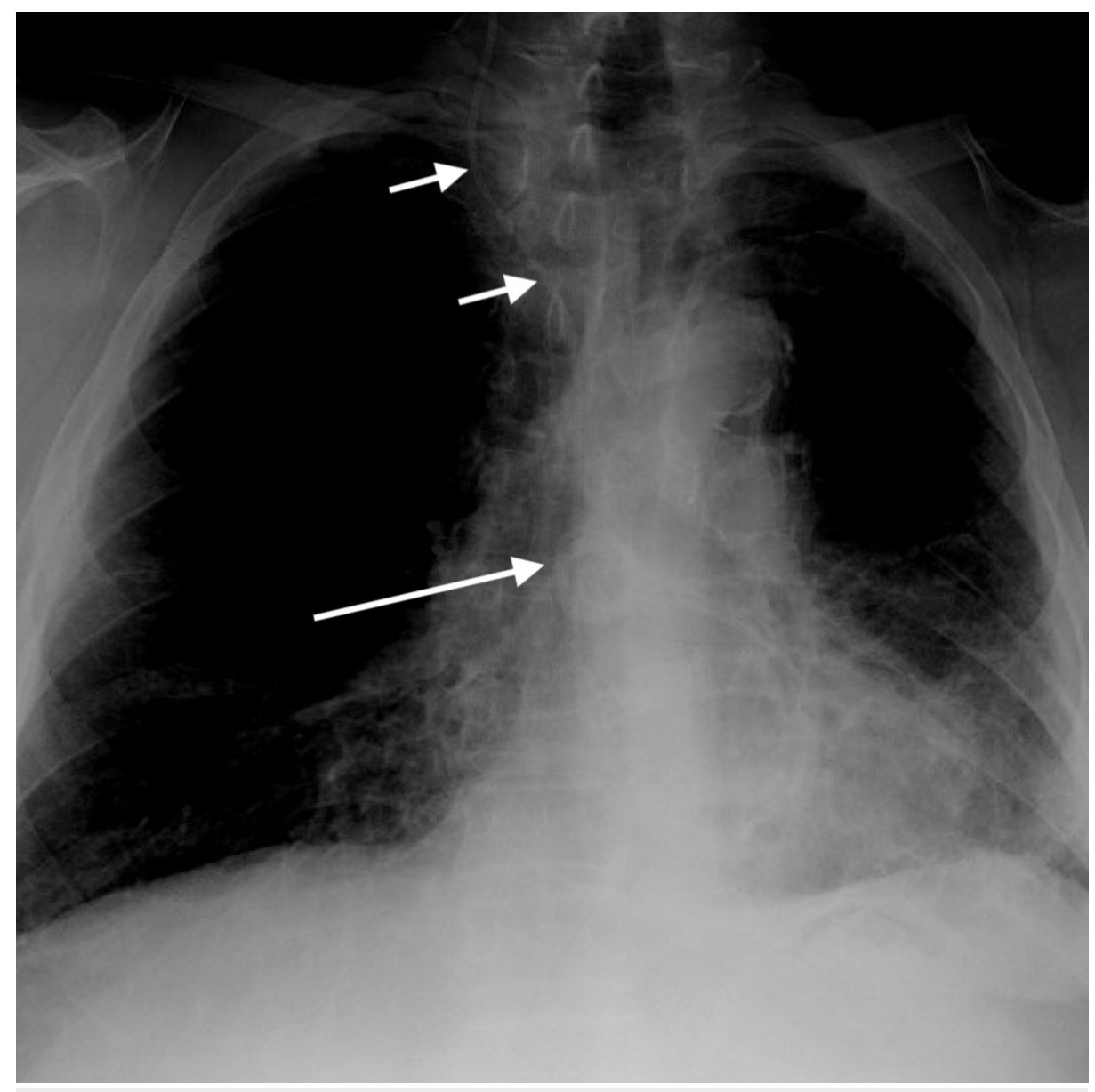

FIGURE 2: Anteroposterior chest X-ray performed as part of a shunt series demonstrates migration of the distal catheter of the ventriculoperitoneal shunt through the superior vena cava (short arrows) and coiling into the right heart (long arrow).

\section{Procedure}

Interventional radiology and cardiothoracic surgery services were consulted. An initial attempt was made to retrieve the migrated catheter proximally by the neurosurgical service. A small retroauricular incision was made, and Isovue-300 ${ }^{\circledR}$ contrast (Bracco Diagnostics, Princeton, NJ, USA) was injected into the shunt catheter at the level of the incision using an angiocatheter. Opacification of the looped catheter was noted within the right atrium, right ventricle, and minimally within the right pulmonary artery segment. Proximal removal of the shunt catheter was attempted under fluoroscopic observation, and approximately $40 \mathrm{~cm}$ of tubing were extracted (Figure 3). 


\section{Cureus}

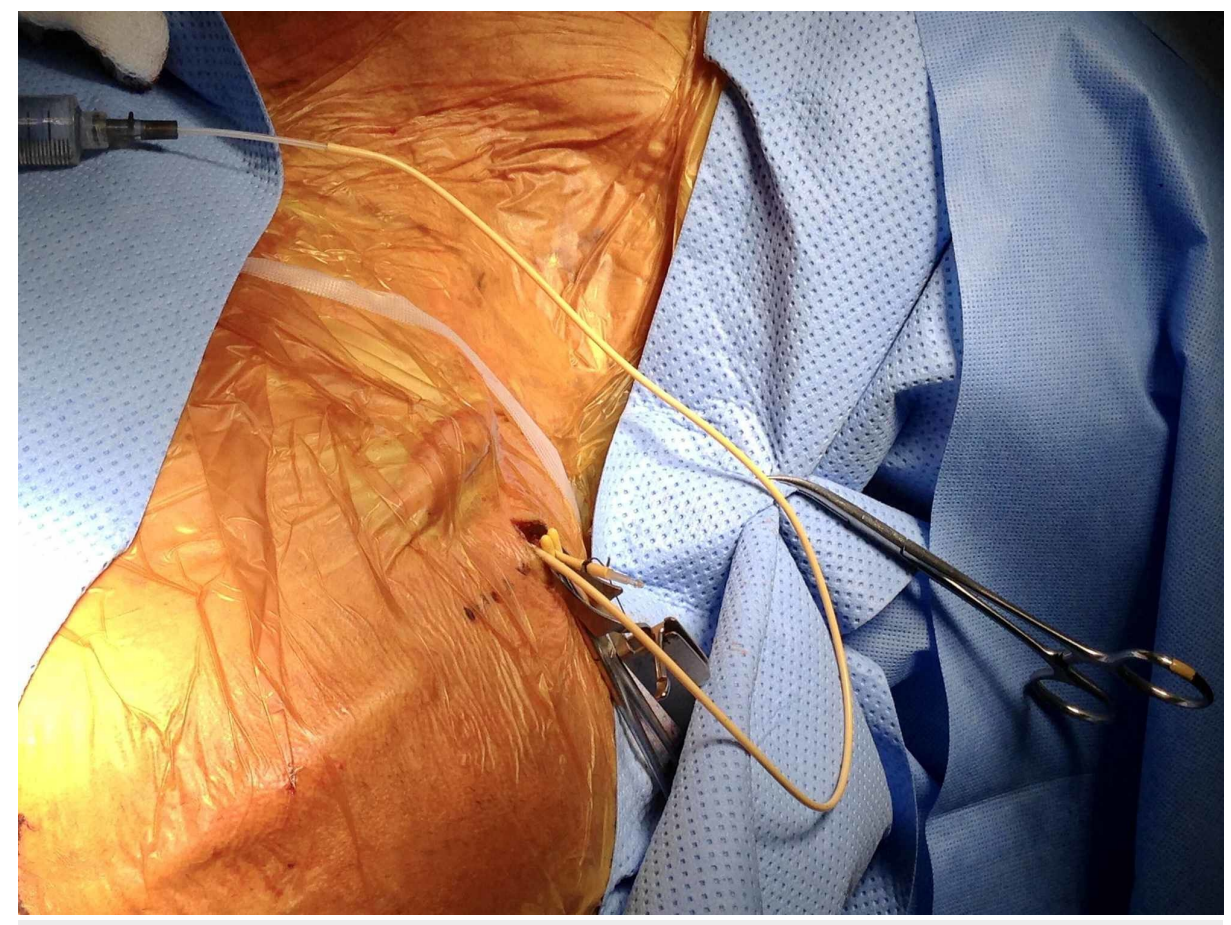

FIGURE 3: Intraoperative photo demonstrates right retroauricular incision with a portion of the distal shunt catheter removed.

At that point, further removal was met with marked resistance, and additional coiling of loops could be seen within the SVC (Figure 4). 


\section{Cureus}

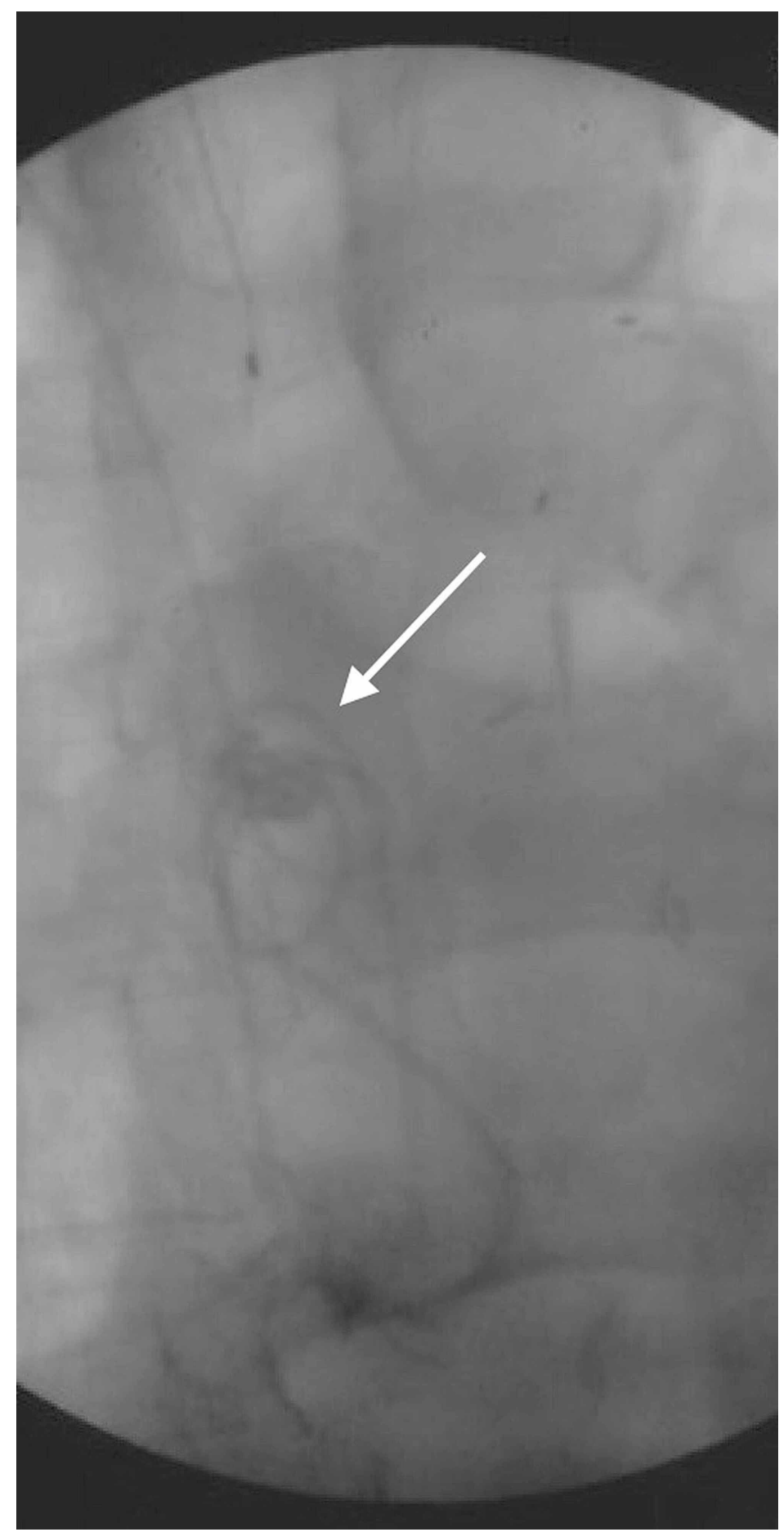

FIGURE 4: Fluoroscopy allows visualization of the catheter coiling in the superior vena cava (arrow) after a portion of the distal catheter had been removed. At this point, resistance was encountered and the attempt at proximal removal was aborted.

The right common femoral vein was then accessed by the interventional radiologist using a 19-gauge singlewall needle. A 7-French sheath was inserted over a J-tipped guidewire. Under fluoroscopic observation, a 5French angled tapered glide catheter was inserted to the SVC through the right atrium. A 2-mm Snare ${ }^{\circledR}$ delivery catheter (Merit Medical, Jordan, UT, USA) was advanced through the right internal jugular vein over a Stork wire. Under fluoroscopic observation, the looped shunt catheter was snared and proximally withdrawn to the right common femoral vein (Figure 5). 


\section{Cureus}

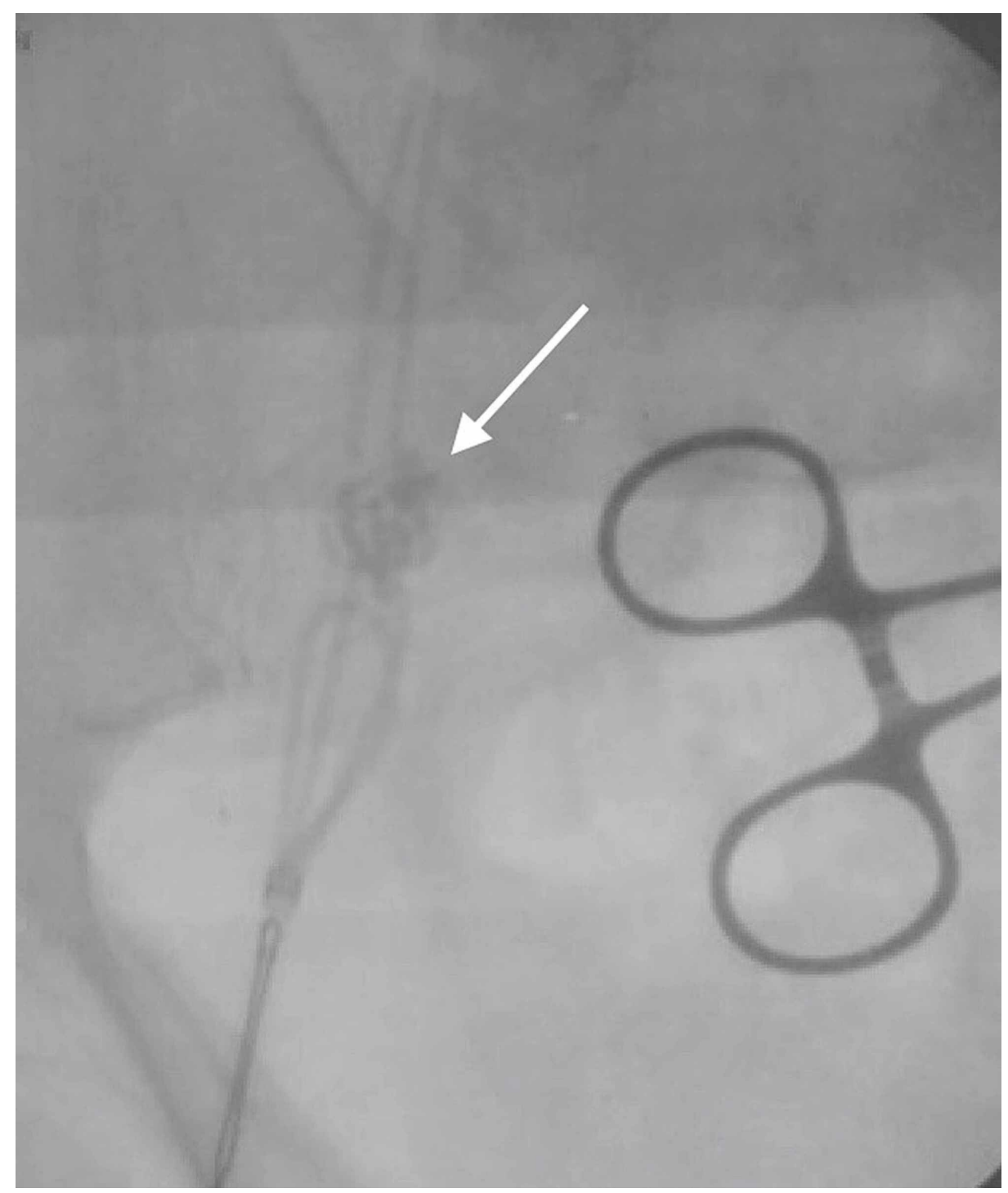

FIGURE 5: The right common femoral vein was accessed and a 2-mm Snare ${ }^{\circledR}$ delivery catheter was advanced over a Stork wire. Under fluoroscopic observation, the looped shunt catheter was snared and withdrawn to the right common femoral vein (arrow), where it was ultimately removed surgically through venotomy.

Prior to withdrawal, a suture was attached to the proximal aspect of the shunt to retain proximal control. The shunt catheter was wedged within the proximal aspect of the right common femoral vein sheath. It was then surgically extracted through common femoral vein transverse venotomy by the cardiothoracic surgeon. The distal catheter was replaced, and placement was confirmed with an abdominal X-ray (Figure o). 


\section{Cureus}

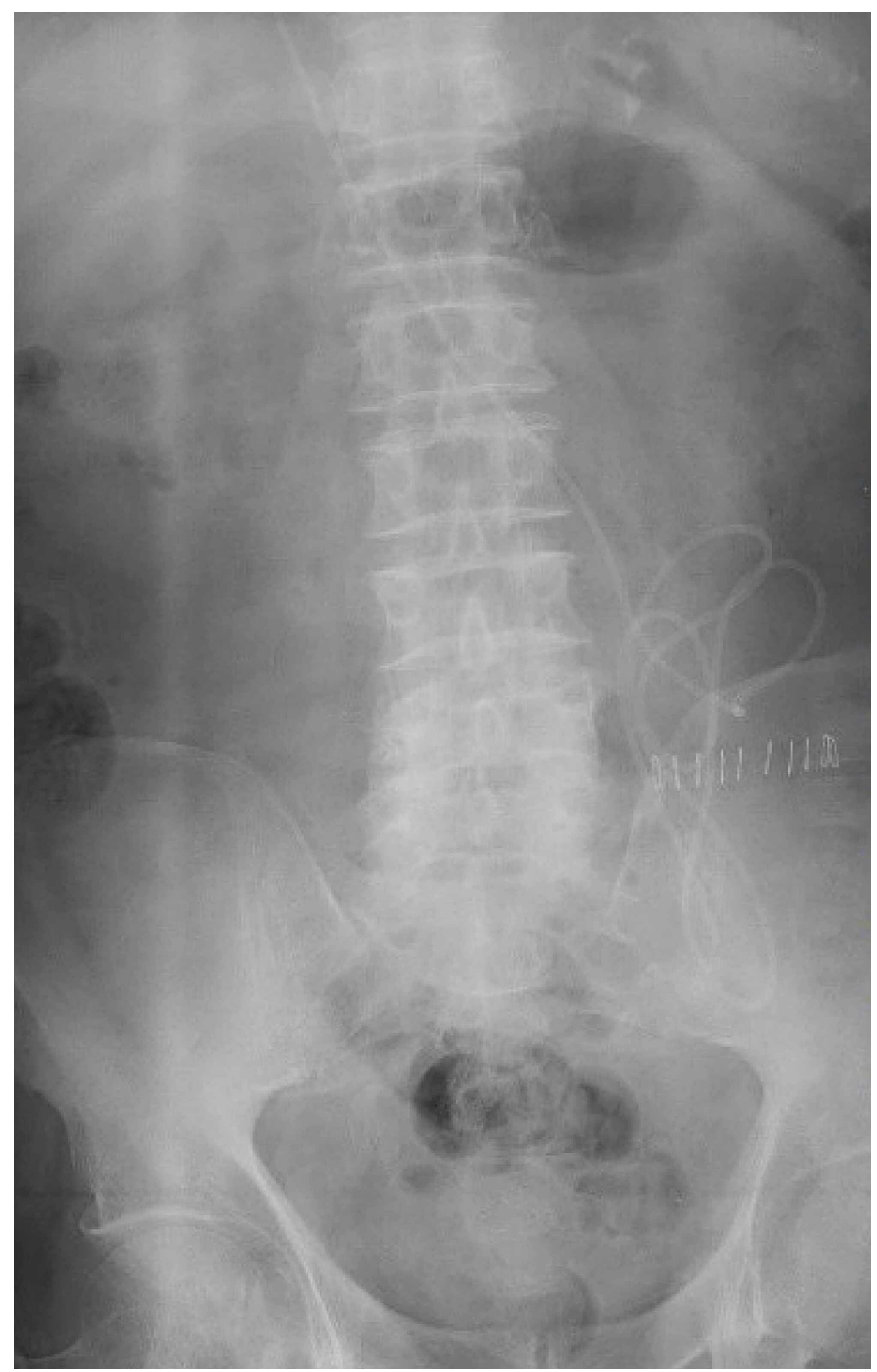

FIGURE 6: Post-operative abdominal X-ray confirms the location of distal catheter in the peritoneum.

\section{Post-operative course}

The patient tolerated the procedure well and was extubated in the operating room. He was discharged home on post-operative day 1 with the shunt valve set to $11 \mathrm{~cm} \mathrm{H}_{2} \mathrm{O}$. He was seen in the office two months after surgery complaining of positional headaches, and the shunt was reset to $12 \mathrm{~cm} \mathrm{H}_{2} \mathrm{O}$. Thereafter, he had no further alterations to the valve setting or shunt catheter.

\section{Discussion}

Roughly $55 \%$ of shunt revisions are unavoidable and typically occur after three months of implantation [5]. Preoperative symptoms such as headache, gait instability, cognitive decline, and urinary incontinence have 
been described in the literature as predictors of shunt malfunction [6]. Obesity and previous shunt surgery are more specific independent risk factors for catheter migration [7]. Distal catheter migration of VP shunts most commonly arises from peritoneal perforation and has been observed in a variety of organ systems such as lumbar soft tissue penetration following discectomy, bladder perforation and extrusion through the urethral orifice, ascension into the oropharyngeal cavity through the gastrointestinal tract, and descension into the scrotum through a congenital remnant [8-11]. Spontaneous intracardiac migration, such as the basis of this case report, has been documented previously in the literature, albeit rarely [12-17].

The exact mechanism surrounding distal catheter migration of this manner is unclear, but several hypotheses have been proposed. Two main theories have dominated the literature. One is that cannulation of the venous system occurs during distal tunneling of the shunt catheter that goes unnoticed intraoperatively $[12,13]$. The second is that the catheter, over time with repeated friction contact, erodes into an adjacent vein. This mechanism has historically been attributed to stiffness of the catheter [12]. The association between reduced occurrence of migration and softer, more flexible catheters suggests that a mechanical component exists in shunt migration [14]. In either case, the migration to the cardiopulmonary system is attributed to negative inspiratory pressure in the thoracic cavity that slowly draws the catheter into the vena cava and subsequently into the right atrium, right ventricle, and pulmonary arteries [15]. Apart from these, age has been shown to correlate with shunt migration, with a bimodal predilection in the early childhood and elderly populations [16]. Weak constitutions, specifically muscle and vasculature, diminish at each end of the aging spectrum and may serve as a predisposing factor.

Revision of VP shunts that spontaneously migrate into intracardiopulmonary system is often necessary to prevent serious complications. Intracardiac migration is conceptually similar to an unsecured ventriculoatrial (VA) shunt. Catheters that migrate into the cardiopulmonary system can become significantly scarred or tethered to cardiac tissue and may require an open heart surgery for extraction [17]. Further migration of the distal catheter past the atrium and into the pulmonary vasculature is problematic as it poses a risk of rapid cardiopulmonary destabilization [18].

Intraoperative fluoroscopy is a reliable method to assess and correct migrating VP shunt catheters and decreases early surgical revisions compared with controls without intraoperative radiography [19]. Interventional radiologists are particularly qualified to assist with endovascular retrieval of foreign bodies such as migrating catheters. For instance, utilization of transfemoral endovascular snaring, as in our case, has been successfully demonstrated in the past with a fragmented VA shunt [20]. However, due to the extensive coiling of catheter that occurred in our case, endovascular snaring was not sufficient to retrieve the catheter outright. After localization with the snare, a venotomy was required to safely withdraw the catheter. We suggest employing a multidisciplinary care team comprising a neurosurgeon, a cardiothoracic surgeon, and an interventional radiologist. This approach allows for flexibility in response to the uncertainty associated with the procedure.

\section{Conclusions}

VP shunt migration into the cardiovascular structures presents unique challenges with surgical revision. Our case demonstrates how a multidisciplinary surgical team is needed to effectively revise a VP shunt after spontaneous migration into the venous and cardiopulmonary vasculature. Further reports of shunt catheter migration would be helpful in evaluating other surgical approaches for catheter revision since no standard of care currently exists.

\section{Additional Information \\ Disclosures}

Human subjects: Consent was obtained by all participants in this study. Conflicts of interest: In compliance with the ICMJE uniform disclosure form, all authors declare the following: Payment/services info: All authors have declared that no financial support was received from any organization for the submitted work. Financial relationships: All authors have declared that they have no financial relationships at present or within the previous three years with any organizations that might have an interest in the submitted work. Other relationships: All authors have declared that there are no other relationships or activities that could appear to have influenced the submitted work.

\section{References}

1. Soler GJ, Bao M, Jaiswal D, Zaveri HP, DiLuna ML, Grant RA, Hoshino K: A review of cerebral shunts, current technologies, and future endeavors. Yale J Biol Med. 2018, 91:313-321.

2. Schenker P, Stieglitz LH, Sick B, Stienen MN, Regli L, Sarnthein J: Patients with a normal pressure hydrocephalus shunt have fewer complications than do patients with other shunts. World Neurosurg. 2018, 110:249-257. 10.1016/j.wneu.2017.10.151

3. Khan F, Rehman A, Shamim MS, Bari ME: Factors affecting ventriculoperitoneal shunt survival in adult patients. Surg Neurol Int. 2015, 6:25. 10.4103/2152-7806.151388

4. Feletti A, d'Avella D, Wikkelso C, et al.: Ventriculoperitoneal shunt complications in the European idiopathic normal pressure hydrocephalus multicenter study. Oper Neurosurg (Hagerstown). 2019, 17:97- 
102. 10.1093/ons/opy232

5. Kaestner S, Poetschke M, Kehler U, Antes S, Krause M, Deinsberger W: Revision surgery following CSF shunt insertion: how often could it be avoided?. Acta Neurochir (Wien). 2020, 162:9-14. 10.1007/s00701-01904083-0

6. Hung AL, Vivas-Buitrago T, Adam A, et al.: Ventriculoatrial versus ventriculoperitoneal shunt complications in idiopathic normal pressure hydrocephalus. Clin Neurol Neurosurg. 2017, 157:1-6.

10.1016/j.clineuro.2017.03.014

7. Abode-Iyamah KO, Khanna R, Rasmussen ZD, Flouty O, Dahdaleh NS, Greenlee J, Howard MA: Risk factors associated with distal catheter migration following ventriculoperitoneal shunt placement. J Clin Neurosci. 2016, 25:46-49. 10.1016/j.jocn.2015.07.022

8. Suryadevara R, Lieber BA, Garcia E, Sood S, Haridas A, Ham S: Migration of a ventriculo-peritoneal shunt catheter into a back incision of a patient with previous spinal fusion. Childs Nerv Syst. 2018, 34:787-789. 10.1007/s00381-017-3689-2

9. Yang X, Liang R, Zhang Y: An unusual complication of ventriculoperitoneal shunt with bladder perforation and extrusion through the urethra orifice in an adult male patient. Int J Neurosci. 2019, 129:101-102. 10.1080/00207454.2018.1486305

10. Mohammadi A, Hedayatiasl A, Ghasemi-Rad M: Scrotal migration of a ventriculoperitoneal shunt: a case report and review of literature. Med Ultrason. 2012, 14:158-160.

11. Low SW, Sein L, Yeo TT, Chou N: Migration of the abdominal catheter of a ventriculoperitoneal shunt into the mouth: a rare presentation. Malays J Med Sci. 2010, 17:64-67.

12. Adib SD, Lescan M, Renovanz M, et al.: Intracardial catheter migration of a ventriculoperitoneal shunt: pathophysiology and interdisciplinary management. World Neurosurg. 2020, 135:222-227. 10.1016/j.wneu.2019.12.089

13. Kang JK, Jeun SS, Chung DS, Lee IW, Sung WH: Unusual proximal migration of ventriculoperitoneal shunt into the heart. Childs Nerv Syst. 1996, 12:176-179. 10.1007/bf00266827

14. Kanojia R, Sinha SK, Rawat J, Wakhlu A, Kureel S, Tandon R: Unusual ventriculoperitoneal shunt extrusion: experience with 5 cases and review of the literature. Pediatr Neurosurg. 2008, 44:49-51. 10.1159/000110662

15. Imamura H, Nomura M: Migration of ventriculoperitoneal shunt into the heart-case report. Neurol Med Chir (Tokyo). 2002, 42:181-183. 10.2176/nmc.42.181

16. Allouh MZ, Al Barbarawi MM, Hiasat MH, Abuzayed BA: Migration of the distal catheter of the ventriculoperitoneal shunt in hydrocephalus patients. Neurosciences (Riyadh). 2017, 22:298-302. 10.17712/nsj.2017.4.20170137

17. Ralston A, Johnson A, Ziemer G, Frim DM: Transcardiac migration of ventriculoperitoneal shunt requiring open cardiac surgery: case report and review of the literature. Childs Nerv Syst. 2017, 33:703-707. 10.1007/s00381-016-3324-7

18. Moses ZB, Ozpinar A, Abd-El-Barr MM, Quinonez LG, Emani SM, Goumnerova LC: Direct heart shunt placement for CSF diversion: technical note. J Neurosurg Pediatr. 2016, 25:663-666. 10.3171/2016.5.PEDS15638

19. Coluccia D, Anon J, Rossi F, Marbacher S, Fandino J, Berkmann S: Intraoperative fluoroscopy for ventriculoperitoneal shunt placement. World Neurosurg. 2016, 86:71-78. 10.1016/j.wneu.2015.08.072

20. Rao AJ, Teton Z, Rodriguez V, Tieu BH, Raslan AM: Distal ventriculoatrial shunt revision in adult myelomeningocele patient performed via endovascular transvenous approach. World Neurosurg. 2019, 121:24-27. 10.1016/j.wneu.2018.09.129 